\title{
Hierarquia racial na era do pós-racialismo norte-americano
}

Flavio Thales Ribeiro Francisco ${ }^{1}$

ALEXANDER, Michelle. The New Jim Crow: mass incarceration in the age of colorblindness. New Press: New York, 2012.

Recentemente, a questão racial nos Estados Unidos voltou aos holofotes da grande imprensa com o caso de Trayvon Martin. O garoto negro, que circulava por uma vizinhança predominantemente branca, onde o pai residia, foi abordado por um segurança que o considerou um elemento suspeito. Martin estava desarmado, mas o enfrentamento acabou com um disparo e a sua morte. Mais de um ano após o assassinato, George Zimmerman, branco de origem latina, foi inocentado a partir da interpretação de uma lei da Flórida sobre legítima defesa por um júri de maioria de mulheres brancas. A indignação, sobretudo por parte da população afro-americana, suscitou um debate sobre os limites do pós-racialismo da era de Barack Obama, marcado por narrativas de uma nova sociedade que havia supostamente superado o racismo.

A ideia de uma sociedade norte-americana livre da raça há um bom tempo vem sendo desafiada por estudos como The New Jim Crow: mass incarceration in the age of colorblindness, escrito por Michelle Alexander, advogada e acadêmica da área do Direito. O seu argumento é o de que as transformações ocorridas no período posterior ao Movimento pelos Direitos Civis não são necessariamente o anúncio de uma era pós-racial, mas de reestruturação das hierarquias raciais em um novo contexto. Alexander, através de uma linguagem preocupada em atingir o público geral, mas sem abrir mão de uma análise rigorosa, se apoia em inúmeros estudos empíricos e em uma ampla bibliografia sobre o encarceramento nos Estados Unidos para retratar como a Guerra às Drogas e o aprisionamento em massa de homens negros possibilitaram uma nova forma de marginalização na sociedade norte-americana. A autora articula importantes referências sobre o assunto como Loïc Wacquant, Gleen Loury e Angela Davis, ex-pantera negra, com dados gerados por instituições privadas e governamentais, propondo a ascensão de um Novo Jim Crow. ${ }^{2}$

A obra foi organizada em seis capítulos, onde Michelle Alexander discute as três formas de hierarquias raciais que se estabeleceram no país (escravidão, Jim Crow e o Novo Jim Crow); a estruturação do aparato jurídico que possibilitou a Guerra às Drogas; a blindagem da justiça do país contra as acusações de racismo; o impacto do encarceramento em massa nos guetos; os paralelos do Novo Jim Crow em relação às outras hierarquias raciais e as justificativas que o legitimam; além dos novos desafios impostos ao ativismo afro-americano.

No primeiro capítulo, a autora desenvolve a sua ideia central, afirmando que as desigualdades raciais nos Estados Unidos não são um legado de um racismo anterior em tempos de pós-racialismo, mas uma nova ordem racial que se organiza em torno da política de encarceramento em massa, considerada no senso comum como livre de práticas racistas. Assim como a escravidão e o Jim Crow, a atual estrutura racista se origina de um pacto entre a elite e os brancos das classes populares onde a branquitude se transforma em capital na política, na economia e nas relações sociais. Nesse sentido, em toda a história do país, de acordo com Alexander, as possibilidades de alianças em torno da ideia de classe entre brancos e negros que

\footnotetext{
${ }^{1}$ Doutorando do Programa de História Social da Universidade de São Paulo.

${ }^{2} \mathrm{O}$ Jim Crow é o termo utilizado pelos norte-americanos para se referir à hierarquia racial e ao conjunto de práticas racistas empregados após a abolição da escravidão no país.
} 
colocassem em risco os projetos das elites sempre foram suprimidas para se forjar a ideia de uma superioridade branca em relação aos negros e outros grupos étnicos.

Para cada uma das três hierarquias raciais que se instauraram na história dos Estados Unidos, Michelle Alexander cita eventos que foram fundamentais para as suas origens. Nos primórdios da escravidão, por exemplo, ainda no período das colônias, trabalhadores negros e brancos viviam em regimes de coerção semelhantes, onde as fronteiras raciais não haviam sido demarcadas. A Rebelião de Beacon, em 1676, na colônia da Virginia, foi o principal levante interracial de muitos que contestaram o poder das elites coloniais. A partir deste evento uma série de leis foram adotadas para afirmar a situação de escravidão perpétua dos negros e aliviar a servidão dos trabalhadores brancos. Já no período posterior à emancipação dos escravos, os grandes proprietários do sul do país lançaram mão de estratégias semelhantes ao varrerem os direitos garantidos aos libertos durante a Reconstrução (1865-1877), desestabilizando alguns esforços de cooperação entre trabalhadores agrícolas negros e brancos. Mais uma vez, para Alexander, se firmava uma aliança entre a elite e o populares brancos, evitando a ascensão de movimentos consistentes de classe e abrindo o caminho para o Jim Crow.

A narrativa da autora situa historicamente os leitores e os prepara para a ascensão da hierarquia racial a ser tratada no livro: a do encarceramento em massa e da guerra contra as drogas. O Novo Jim Crow surge a partir do esgotamento do Movimento pelos Direitos Civis (1954-1968), quando setores da população branca do país que apoiavam a agenda política dos ativistas passaram a se ressentir com os "excessos" do movimento, sobretudo durante a crise econômica na década de 1970. As estratégias de grupos radicais foram consideradas não como práticas do jogo político, mas como subversivas e criminosas. Os republicanos, que assistiam a hegemonia do Partido Democrata desde Franklin Roosevelt (1933-1945), se rearticularam nos anos 70, procurando responder as expectativas do eleitorado branco com a elaboração de uma agenda conservadora. A eleição de Ronald Reagan, em 1981, cumpriu, então, a função de colocar em prática um novo pacto entre diferentes camadas da população branca norte-americana.

A era de Reagan, segundo as colocações de Alexander, foi responsável por uma ofensiva a muitos dos programas sociais de administrações anteriores, reforçando sempre a necessidade de se cortar os gastos do Welfare State. O presidente não se furtou de criticar os dependentes de serviços sociais que não haviam aderido à ética do trabalho, tratando-os como desocupados. Os discursos de Ronald Reagan logo ganharam conotações raciais ao fazer a associação implícita entre a população negra e os dependentes dos serviços públicos. Sem se utilizar a linguagem dos tempos do Jim Crow, se reelaborava e recontextualizava a visão racista de negros poucos aptos ao trabalho e com tendências criminosas. Com oportunidades reduzidas devido à crise econômica e à globalização, já que postos de trabalhos na indústria se transferiam para outros países em busca mão de obra barata, o subemprego e os auxílios se transformavam em meios únicos para as populações negras em diversas cidades do país.

O golpe fundamental para afirmação do Novo Jim Crow seria dado com a Guerra às Drogas. O tráfico e o consumo de crack, também associados aos negros, se transformariam em problemas fundamentais da sociedade norte-americana. Impulsionados pelos discursos do Ronald Reagan contra as drogas, recursos aplicados em áreas sociais foram direcionados para a luta contra o narcotráfico. Ainda que a população branca fosse a maior consumidora de drogas, os negros se transformariam em alvos principais das forças policiais. A relação que se fazia entre população negra e criminalidade, que vinha desde os finais dos anos 1960, passou a ser considerada como fenômeno natural. Assim, uma série de leis rigorosas contra as drogas foi aprovada, implicando em penas desproporcionais para traficantes e usuários. Conforme argumenta Michelle Alexander, se iniciava o encarceramento em massa com novos métodos de controle sobre os negros que se estendiam da prisão até a liberdade com restrições ao acesso a 
serviços públicos e ao direito de voto. Desta vez, contudo, o pacto entre diferentes segmentos da população branca não teria uma clara conotação racial, a guerra contra as drogas seria rígida "para todas as raças".

Nos dois capítulos seguintes, a autora procura retratar as engrenagens que mantêm o funcionamento do Novo Jim Crow. Alexander demonstra como um conjunto de leis foram articuladas para que a polícia agisse sem que fosse constrangida por qualquer impasse jurídico. Os membros da justiça norte-americana, levados pela euforia da Guerra às Drogas, fizeram interpretações jurídicas que passaram por cima da quarta emenda da constituição, que proíbe a busca ou apreensão policial sem que haja alguma justificativa razoável, abrindo caminho para o emprego da repressão nos guetos de diferentes cidades do país. O mesmo esforço da justiça pôde ser identificado em leis que garantiam o uso de recursos apreendidos em buscas à procura de drogas em operações futuras, garantindo aos policiais poderes sobre o patrimônio de pessoas que sequer haviam sido condenadas.

Ainda que todo o aparato repressivo direcionado aos negros fosse justificado por argumentos de caráter não racial, dados apresentados por uma variedade de pesquisas sobre a repressão ao narcotráfico e o sistema penitenciário tendiam a provar o contrário. Michelle Alexander lança mão de números expressivos para demonstrar o impacto da Guerra às Drogas sobre a população negra. Assim que os investimentos chegaram às divisões de combate aos narcóticos, os números de prisões de negros quadruplicaram, numa escala desproporcional em relação aos brancos. Embora dados como o do Instituto Nacional contra Abuso de Drogas indicassem que jovens brancos consumiam o crack oito vezes mais que os jovens negros, ou maconha sete vezes mais, os negros representavam 80 a 90 por cento dos condenados por tráfico e consumo de drogas.

Para autora, parte do problema está na condução da justiça por um de seus agentes mais poderosos: os promotores. Estes atuam com ampla margem de liberdade e com autoridade para processar supostos "criminosos" ou interromper investigações baseados em evidências pouco consistentes. Para exemplificar, Alexander citou experiências individuais como a de Emma Stewart, mulher negra apanhada em uma operação policial no estado do Texas. Embora inocente, foi encarcerada, ainda que as demais pessoas envolvidas no mesmo caso, todas elas brancas, tenham sido liberadas. Em uma situação como essa, é de costume o promotor forçar a declaração de culpa por parte do acusado ou encaminhar o julgamento com a ameaça de uma condenação muito maior. Stewart, convicta de sua inocência, não assumiu a culpa, mas foi forçada a permanecer em cárcere. Após um mês sem avanços, se declarou culpada por participação no tráfico de drogas, preocupada com a situação dos filhos que não tinham outros responsáveis. Como parte da negociação com a promotoria, ela foi condenada a pagar um valor de mil dólares para ser liberada. Ainda que retomasse a sua "liberdade", Emma Stewart continuaria com o rótulo de criminosa, pois seria proibida, como ex-condenada, pela rigorosidade da lei de morar em habitações públicas, receber cupons de alimentos e, principalmente, votar por cerca de doze anos. Algum tempo depois, a justiça considerou que o informante da operação que encarcerou Stewart havia mentido. Ela, no entanto, continuou considerada como ex-condenada e com direitos limitados.

No quarto capítulo, Michelle Alexander trata justamente do sofrimento de condenados e suas famílias, a sua intenção é a de demonstrar como a experiência carcerária determina os destinos de milhões de pessoas mesmo depois da liberdade, comprometendo o exercício da cidadania. Os ex-condenados passam a fazer parte de um mundo paralelo da informalidade, impedidos de acessar serviços públicos e com a perspectiva sempre presente de retorno para a cadeia. Ao contrário do que se imagina, as famílias do gueto não glorificam os traficantes de drogas e condenados, procuram esconder qualquer vestígio das experiências carcerárias, se 
silenciando sobre os membros que foram presos. Alexander argumenta que a glamorização do tráfico de drogas presentes na cultura Hip-Hop funciona como uma espécie de inversão do estigma em torno da imagem dos negros associada à criminalidade. O problema, no entanto, reside no fato de que a reelaboração de uma identidade gangster estimula as práticas criminais, retroalimentando todo o sistema arquitetado para manter os negros de áreas pobres nas margens do sistema político, longe de exercer a cidadania de maneira plena.

O quinto capítulo retoma alguns argumentos já tratados anteriormente para a autora concluir a sua tese de que a Guerra às Drogas e o encarceramento em massa estruturaram uma nova hierarquia racial que atinge os brancos, mas marginaliza os negros em uma escala profundamente desproporcional. Michelle Alexander entende que a sociedade norte-americana não considera o encarceramento em massa de negros como racismo porque a principal referência é a violência do Jim Crow e, principalmente, de práticas individuais de discriminação racial. Existe uma grande dificuldade de se identificar os traços do racismo institucional, que se manifesta de maneira silenciosa sem utilizar em sua linguagem quaisquer termos de uma "tradicional" cultura racista. Michelle, então, utiliza uma metáfora interessante criada pela filósofa Iris Marion Young para entender o racismo estrutural. "Não é possível compreender a função de uma gaiola quando se dá atenção apenas para as barras ou as janelas individualmente, é necessário entender o modo como elas estão organizadas para poder identificar a estrutura que aprisiona os pássaros”. As instituições do racismo norte-americanas não foram criadas para discriminar e oprimir minorias raciais, mas articuladas possibilitam o encarceramento e a marginalização delas.

Enfim, no último capítulo, Alexander tece algumas considerações sobre os rumos do ativismo negro nos Estados Unidos. Para ela, as lideranças devem repensar as estratégias do ativismo negro nos Estados Unidos. As suas ações se restringem a uma elite de advogados sem conexões com a população negra que sofre com os impactos do encarceramento em massa. A agenda política atual é reformista, considera a inclusão dos negros na atual estrutura social, entretanto esta continua a ser sustentada por uma hierarquia racial. As mudanças devem ser muito mais profundas, com um debate sincero sobre raça e com estratégias que contemplem os brancos de classe populares, que se beneficiam de uma branquitude, mas que não conseguem uma estabilidade econômica prometida pela elite branca dos Estados Unidos. Nesse sentido, cabe aos ativistas negros o convencimento da população branca das margens que o beneficio racial implica em perdas econômicas, que alianças com outros grupos em uma estratégia de classe podem desestruturar o encarceramento em massa e criar as bases para uma ordem social mais democrática.

A obra de Michelle Alexander, apesar de ter como foco o encarceramento em massa dos negros nos Estados Unidos, possibilita aos leitores brasileiros interessados nas relações raciais do país a compreensão de um quadro amplo da sociedade norte-americana. Embora o Brasil e os Estados Unidos tenham histórias distintas, a autora traz elementos interessantes de uma nova ordem racial, que assim como a brasileira, combina discursos que afirmam a superação da raça com a reestruturação de hierarquias raciais. Os dois países que foram tratados quase como antípodas na interpretação das ciências sociais durante grande parte do século XX, parecem trilhar caminhos próximos e paralelos no universo das relações raciais. Seja em um ou em outro, a história demonstra mais as reconstituições das desigualdades raciais do que progresso no sentido de destruí-las. 